\title{
MASS TRANSFER FROM A FREELY MOVING SINGLE SPHERE TO THE DENSE PHASE OF A GAS FLUIDIZED BED OF INERT PARTICLES
}

\author{
W. PRINS, * T. P. CASTELEIJN, W. DRAIJER and W. P. M. VAN SWAAIJ \\ Department of Mechanical Engineering, Twente University of Technology, P. O. Box 217, \\ 7500 AE Enschede, The Netherlands
}

(Received 25 September 1983; accepted 23 March 1984)

\begin{abstract}
Naphthalene spheres (particle diameter $2<d_{n}<20 \mathrm{~mm}$ ) were vaporized in beds fluidized by air at a temperature of about $65^{\circ} \mathrm{C}$. The bed material consisted of inert glass beads or alumina in the size range $100<d_{p}<700 \mu \mathrm{m}$. Mass transfer coefficients were measured by determining weight loss with time, as a function of $d_{n}, d_{p}$ and the fluidization velocity $U$. The ratio $d_{n} / d_{p}$ has been varied from 3 to 200 . An interesting conclusion might be that there is no influence of the fluidization velocity on these transfer

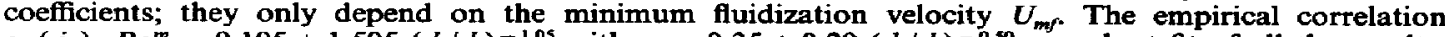
$\epsilon_{m f}\left(j_{D}\right)_{m f} R e_{m f}^{m}=0.105+1.505\left(d_{n} / d_{p}\right)^{-1.05}$ with $m=0.35+0.29\left(d_{n} / d_{\rho}\right)^{-0.50}$, as a best fit of all the results, is accurate within $15 \%$. At $d_{n} / d_{p}=1$ it links up very well with the results of Hsiung and Thodos. For large values of $d_{n} / d_{p}$ agreement with known results of mass transfer measurements between a fluidized bed and a wall or an object is good.
\end{abstract}

\section{INTRODUCTION}

The present research has been actuated by the problem of mass transfer in coal particle combustion. The combustion rate of a single coal particle in a fluidized bed is an important parameter in reactor modelling of $F B C$ to predict the mass of combustibles and the coal particle size distribution in the bed in relation to the combustion efficiency. In general the combustion rate is modelled either according to the assumption of mass transfer limitation only, or according to the assumption of combined mass transfer and surface kinetic control[1]. When estimating the mass transfer rate some authors take $S h=2$ (or a somewhat smaller value as a consequence of the porosity and tortuosity of the dense phase), effectively assuming a stagnant gas situation in the particulate phase of a fluidized bed [2-4]. Others however, maintain that velocities and coal particle sizes as found in FBC's affect the Sherwood number to an extent that cannot be neglected; they use the well known Ranz-Marshall correlation [5] of the Sherwood number for an isolated single sphere: $S h=2+0.6 \operatorname{Re}^{0.50} S^{0.33}[6-10]$.

In the present investigation an attempt was made to determine the mass transfer factor for single spheres freely moving in a gas fluidized bed of inert particles. This is not only important in relation to fluidized bed combustion but also to other processes in which mass transfer is involved, like drying of freely moving objects, gasification of fossil fuels and several non-catalytic treating processes.

*Author to whom correspondence should be addressed

\section{PREVIOUS WORK}

Although an impressive amount of mass transfer data, concerning gas solid systems, have been presented in literature over the last decennia, only a few papers deal with the special case of mass transfer from active particles dispersed in a matrix of inert material. For fluidized bed combustion such a diluted system occurs, as only a small amount of particles are actually reactive. The behaviour of a diluted system is essentially different from an all particles active (pure) system because boundary conditions are not the same (see, e.g. Schlünder[11]). This has not always been recognized as such. Diluted systems, however, have been used in view of their experimental advantages. Thoenes and Kramers [12] applied the method of dilution for fixed bed measurements with arguments to minimize complications caused by bed inhomogeneities, the effect of axial diffusion, the influence of bed height and uncertainty about the actual driving force. At about the same time Bar-Ilan and Resnick [13] presented results of measurements of the rate at which naphthalene particles in a fixed bed vaporized into air passing through the bed. The bulk of the bed consisted of inert material (polystyrene spheres) of size and shape similar to that of the naphthalene particles. Their main argument to use a diluted bed was to avoid saturation conditions in the gas leaving the bed, when large bed heights were applied. The same development has taken place in research on gas particle mass transfer in fluidized beds. In their all particles active fluidized bed experiments Resnick and White[14] and also Chu et al.[15] were restricted to very small bed heights. Relevant to 
the present work is the investigation on mass transfer in diluted gas fluidized beds by Hsiung and Thodos [16]. Here again, the technique of dilution enabled the application of deeper beds while preventing saturation conditions. After an analysis of data obtained from several studies, Hsiung and Thodos concluded that the use of a log mean driving force $\Delta c$ presents an oversimplification of the complex hydrodynamic behaviour of a fluidized bed. Therefore they measured concentration profiles of naphthalene in the flow of air through fluidized beds consisting of naphthalene spheres diluted with inert particles (styrene divinylbenzene copolymer) of a similar geometry, particle size and solid density. The actual driving force however, might be difficult to measure due to the presence of bubbles with a gas composition different from the dense phase.

Special problems arise in fluidized bed mass transfer experiments using the method of naphthalene vaporization: (i) the risk of mechanical erosion of the test sample; and (ii) adsorption of naphthalene by the bed material. If naphthalene vapor is adsorbed on a bed material mass transfer seems to increase considerably[17]. Bed particles that travel through the boundary layer around the naphthalene sample, and having a certain mass capacity, will pick up some naphthalene vapor to release it elsewhere in the bed. Ziegler and Holmes [18] who measured mass transfer rates rates from a flat naphthalene plate to a gas fluidized bed $\left(45^{\circ} \mathrm{C}\right)$ of fused alumina particles, showed that abraded material was normally less than $3 \%$ of the total transfer. Baskakov and Suprun [19] measured mass transfer rates from cylindrical naphthalene samples, fixed vertically in a fluid bed. For beds of corundum particles they proved that neither mechanical erosion of the sample nor adsorption of naphthalene by the bed material do effect the results at temperatures over $60^{\circ} \mathrm{C}$. Supported by these experiences, experimental conditions could be chosen so that the above mentioned problems were eliminated. Special experiments, discussed furtheron in this paper, will demonstrate the validity of this statement.

Recently Tamarin [20] presented a model of boundary layer and suspension conditions of a solid particle in a gas flow in order to formulate an analytical expression that could describe gas particle mass transfer in a fluidized bed. The background of this theoretical investigation was the question of mass transfer to a coal particle in fluidized bed combustion. He compared his expression with the experimental data of Hsiung and Thodos[16] and also referred to results of some combustion experiments (cited in Refs. [7] and [8]) available in Russian literature. The paper of Tamarin unfortunately lacks direct experimental evidence on the influence of the ratio of the test particle and bed particle diameter. Moreover, the way of interpretation of combustion experiments to mass transfer rates is left rather in the dark. First of all one could raise the question whether $\mathrm{CO}$ oxidation takes place in or outside the boundary layer.
Secondly, the temperature of the coal particle certainly differs considerably from the bed temperature causing uncertainty in the transport properties. Finally a possible ash layer around the coal particle might introduce an additional mass transfer resistance.

The above mentioned objections have been recognized (but only partially overcome) by La Nauze and Jung[21], who measured mass transfer rates from diffusion limited combustion of petroleum coke particles in a fluidized bed of river sand particles.

The work presented in this paper can be considered as an extension of the research done by Hsiung and Thodos[16] and is not restricted to the similarity in geometry, particle size and solid density of the naphthalene samples and bed particles. The experimental data of La Nauze and Jung[21] will be reanalyzed to compare them with the results of the present investigation.

The important conclusion of Van Heerden et al. [17] that the mass transfer rate in a fluidized bed is essentially the same as in a fixed bed of the same particles and at the same gas velocity (in contrast with the conception in which the moving bed particles are considered to be effective turbulence promotors) will be checked. Furthermore the interesting question of analogy between mass and heat transfer in fluidized beds will come up in connection with the results of some mass transfer measurements in naphthalene adsorbing bed materials. Finally the analytical expression derived by Tamarin to predict mass transfer rates from freely moving objects in a gas fluidized bed will be tested.

\section{EXPERIMENTAL}

The experimental equipment used is shown in Fig. 1. Air taken from the laboratory supply line was passed through a constant temperature bath before it entered the fluidized bed section.

Details of this section are given in Fig. 2. The fluidized bed was constructed of steel and had the following dimensions: internal diameter $12.7 \mathrm{~cm}$, length $55 \mathrm{~cm}$. Two perforated steel plates combined with a layer of cotton-wool between them served as a distributor. The pressure drop over the distributor

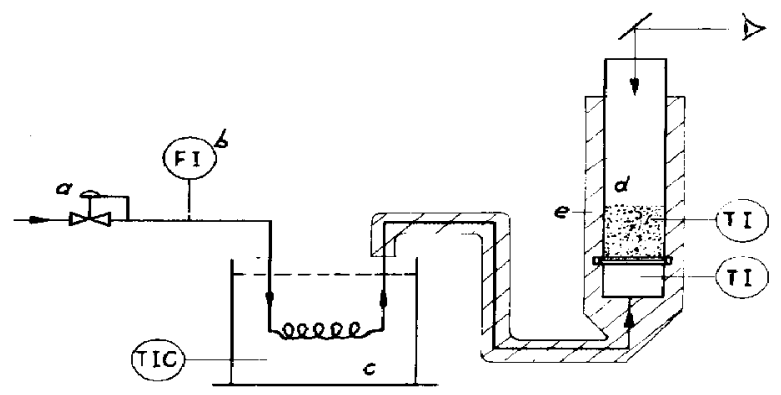

Fig. 1. Flow diagram of the equipment; (a) reduction valve; (b) critical flow nozzle; (c) constant temperature bath; (d) fluid bed unit; (e) insulation. 


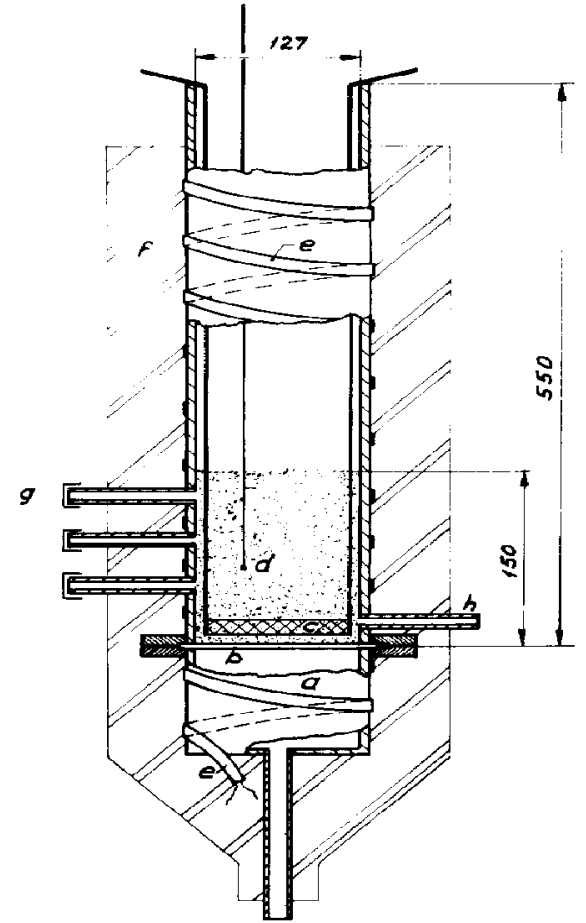

Fig. 2. Schematic diagram of the fluid bed unit: (a) calming section; (b) porous steel distributor; (c) sieve device; (d) thermocouple; (e) heating wire; (f) insulation (g) gas sample points; (h) pressure tap

was large enough to ensure a uniform gas flow over the cross section of the bed in each experiment. The whole unit was insulated with glass-wool and kept at a temperature of $65^{\circ} \mathrm{C}$. Properties of the bed material are summarized in Table 1 . The solid density of naphthalene at $65^{\circ} \mathrm{C}$ was taken $1015 \mathrm{~kg} / \mathrm{m}^{3}[22]$, and the diffusion coefficient calculated from $D=5.13 \times 10^{-6}(T / 273.15)^{1.75}[23]$. The kinematic viscosity of air being $19.5 \times 10^{-6} \mathrm{~m}^{2} / \mathrm{s}$ at that temperature yields a value of $\mathbf{2 . 6}$ for the Schmidt number. Bed porosities at minimum fluidization have been established by extrapolating a plot of the average bed porosity (obtained by measuring the bed expansion) versus $U / U_{m f}$ to the value $U / U_{m f}=1$.

At the beginning of each experiment one naphthalene sphere of known weight and diameter was brought into a fully fluidized bed of $15 \mathrm{~cm}$ height. Fluidizing velocity was large enough in any case to prevent segregation which would cause the naphthalene sample to float on the top of the bed. This could easily be checked by visual observations. After a certain time the naphthalene sample was removed from the bed by lifting a sieve device resting on the bottom of the bed during the experiment. Weight loss was measured and the value of the mass transfer coefficient was calculated from the formula

$$
k=(\Delta G / \Delta t) / \pi d_{n}^{2} \Delta c
$$

in which $\Delta G / \Delta t$ is the weight loss of the naphthalene sample in time; $\pi d_{n}^{2}$ is the average surface area (diameter decrease was negligible during each experiment); $\Delta c$ is the driving force, or difference between the naphthalene vapor concentration at the sample surface and in the bulk of the bed, $\Delta c=c^{*}-c_{0} \approx c^{*}$. The concentration of naphthalene vapor in the bulk of the bed has been measured in a number of cases with the aid of the MIRAN 80 infrared analyzer and proved to be always less than $1 \%$ of the saturated concentration at the naphthalene surface, even for measurements at the top of the bed. So we may say that $\Delta c$ is practically equal to $c^{*}$ and that the driving force is maximal in each experiment. The value of the saturated naphthalene concentration for different temperatures was determined from the formula

$$
\log _{10} p^{*}=11.450-3729.3 / T
$$

\begin{tabular}{|c|c|c|c|c|c|c|}
\hline & & ${ }_{0}\left(k g / m^{3}\right)$ & $d_{p}(\mu m)$ & $\bar{d}_{p}(\mu w)$ & $U_{\text {inf } f}(c m / a)$ & $\varepsilon_{\operatorname{mf}}$ \\
\hline \multirow{6}{*}{\multicolumn{2}{|c|}{ glass beads }} & 2800 & $84-116$ & 98 & 1.20 & 0.381 \\
\hline & & 26.20 & $84-178$ & 131 & 1.85 & 0.384 \\
\hline & & 2870 & $170-280$ & 229 & 6.5 & 0.400 \\
\hline & & 2850 & $420-490$ & 460 & 26.5 & 0.343 \\
\hline & & 2830 & $448-569$ & 516 & 26.5 & 0.378 \\
\hline & & 2850 & $550-700$ & 620 & 36.0 & 0.355 \\
\hline \multirow{2}{*}{\multicolumn{2}{|c|}{ dense alumina }} & 3390 & $600-730$ & 669 & 40.5 & 0.369 \\
\hline & & 3390 & $680-810$ & 739 & 48.0 & 0.390 \\
\hline poraus & a Iuma & 1800 & $550-580$ & 564 & 18.1 & 0.433 \\
\hline si11ca & sand & 2600 & $100-300$ & 230 & 4.75 & 0.443 \\
\hline
\end{tabular}

Table 1. Physical properties of bed material $\left(65^{\circ} \mathrm{C}\right)$ 
Table 2. Naphthalene adsorption on various bed materials $\left(65^{\circ} \mathrm{C}\right)$

\begin{tabular}{|c|c|c|c|}
\hline bed mater 1 al & average particle & average & adsorption \\
\hline & dianter ( $u m)$ & spheric1ty & capac1ey (mg/g) \\
\hline g1ass beads & 229 & 1.0 & 0.0 \\
\hline glass beads & 620 & 1.0 & 0.0 \\
\hline stilica sand & 200 & 0.8 & 0.2 \\
\hline porous alumina & 564 & 1.0 & 25.0 \\
\hline dense alumina & 669 & 1.0 & 0.0 \\
\hline polystyrene beads & 600 & 1.0 & 9.0 \\
\hline
\end{tabular}

in which $p^{*}(\mathrm{~mm} \mathrm{Hg})$ is the partial saturated vapor pressure at a temperature of $T(\mathrm{~K})$ [24]. $c^{*}$ was calculated from $p^{*}$ by assuming ideal gas behaviour.

\section{SELECTION OF BED MATERIAL}

The main objective of the present work is to establish mass transfer coefficients in non adsorbing, non abrading bed materials. To select such a material first of all adsorption capacities, expressed as milli- gram naphthalene per gram bed material, have been measured at a temperature of $65^{\circ} \mathrm{C}$ in a small fixed bed arrangement (bed height $50 \mathrm{~mm}$, bed diameter $17 \mathrm{~mm}$ ). While passing a nitrogen gas stream saturated with naphthalene vapor through it, weight increase was recorded until steady state conditions were attained. From this analysis we concluded that only glass beads or dense alumina microspheres could be used as a bed material (see Table 2). Although other

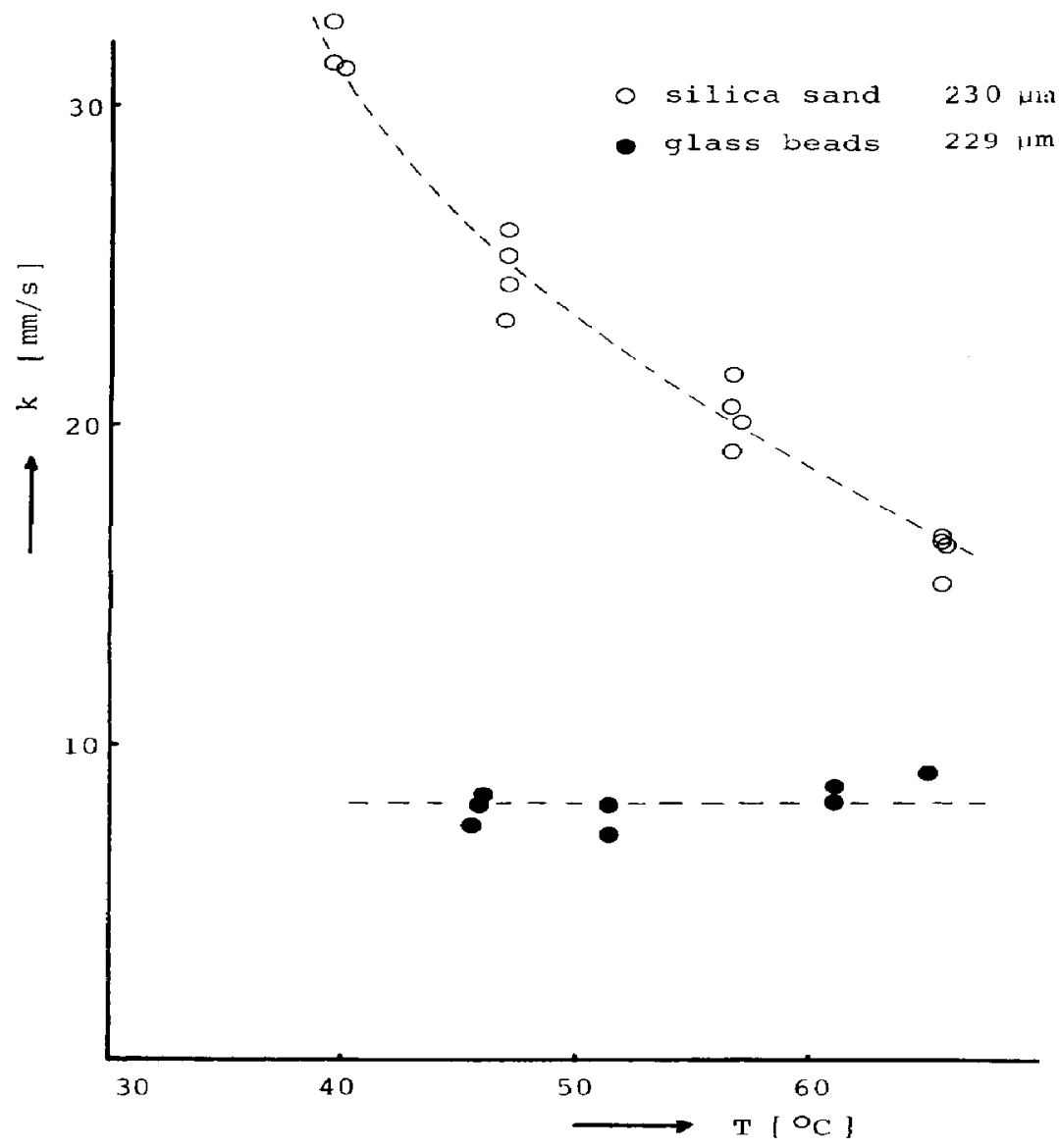

Fig. 3. Variation of observed mass transfer coefficient with temperature for a 14 mm naphthalene sphere in gas fluidized beds of two different bed materials; $U / U_{m f}=2$. 
investigators $[18,19]$ proved conclusively the effect of mechanical erosion to be negligible in these kind of experiments, it was rather easy to check this by measuring mass transfer rates over a range of temperatures for the bed materials in question. When the temperature is increased from 35 to $65^{\circ} \mathrm{C}$ the total amount of sublimated naphthalene sharply rises due to a substantial increase of the saturated vapor pressure (more than a factor 10). The intensity of attrition however, is practically unchanged. So if a significant part of the total flux of naphthalene from the surface at $65^{\circ} \mathrm{C}$ was due to attrition, the mass transfer coefficient would seem to increase at lower temperatures. This is certainly not the case for beds of spherical glass beads and of dense alumina particles as can be seen from the Figs. 3 and 4. Although attrition cannot be excluded for the results of the two other bed materials presented in these figures, we may say now that it is not likely to happen. For fluidized beds of sand particles or porous alumina microspheres the increase in mass transfer coefficient at lower temperatures most probably is a consequence of the increasing adsorption capacity of the bed material. In general one may say that spherical, non porous particles have preference to be used as a bed material in order to overcome the problems of me- chanical erosion and/or adsorption of naphthalene on the bed material.

\section{ANALYSIS OF EXPERIMENTAL RESULTS}

Infuence of $\mathrm{d}_{\mathrm{p}}, \mathrm{U}$ and $\mathrm{d}_{\mathrm{n}}$

Results of mass transfer measurements in five different sized bed materials are presented in Fig. 5. It is evident that larger bed materials give higher transfer coefficients: in the fluidized bed the velocity of the gas around the naphthalene test particle is expected to be closely related to the velocity for the initiation of fluidization $\left(U_{m f}\right)$. Although the presence of bubbles or an increased turbulence could be expected to have some positive influence on the total mass transfer rate, Fig. 6 shows on the contrary that no effect of the fluidizing velocity can be observed over the complete range of bed materials. This is the same conclusion as can be drawn from the results of Hsiung and Thodos[16] for their measurements at $d_{n}=d_{p}:$ a plot of $\log \left\{j_{n} /\left(j_{D}\right)_{m j}\right\}$ vs $\log \{R e /$ $\left.\left(1-\epsilon_{m f}\right) R e_{m f}\right\}$, including all the runs of their study showed a slope -1 . (It should be noticed, however, that the measurements of Hsiung and Thodos were carried out in generally at rather low bed depths.) The decrease of mass transfer coefficients with increasing diameter of the naphthalene test sample most probably

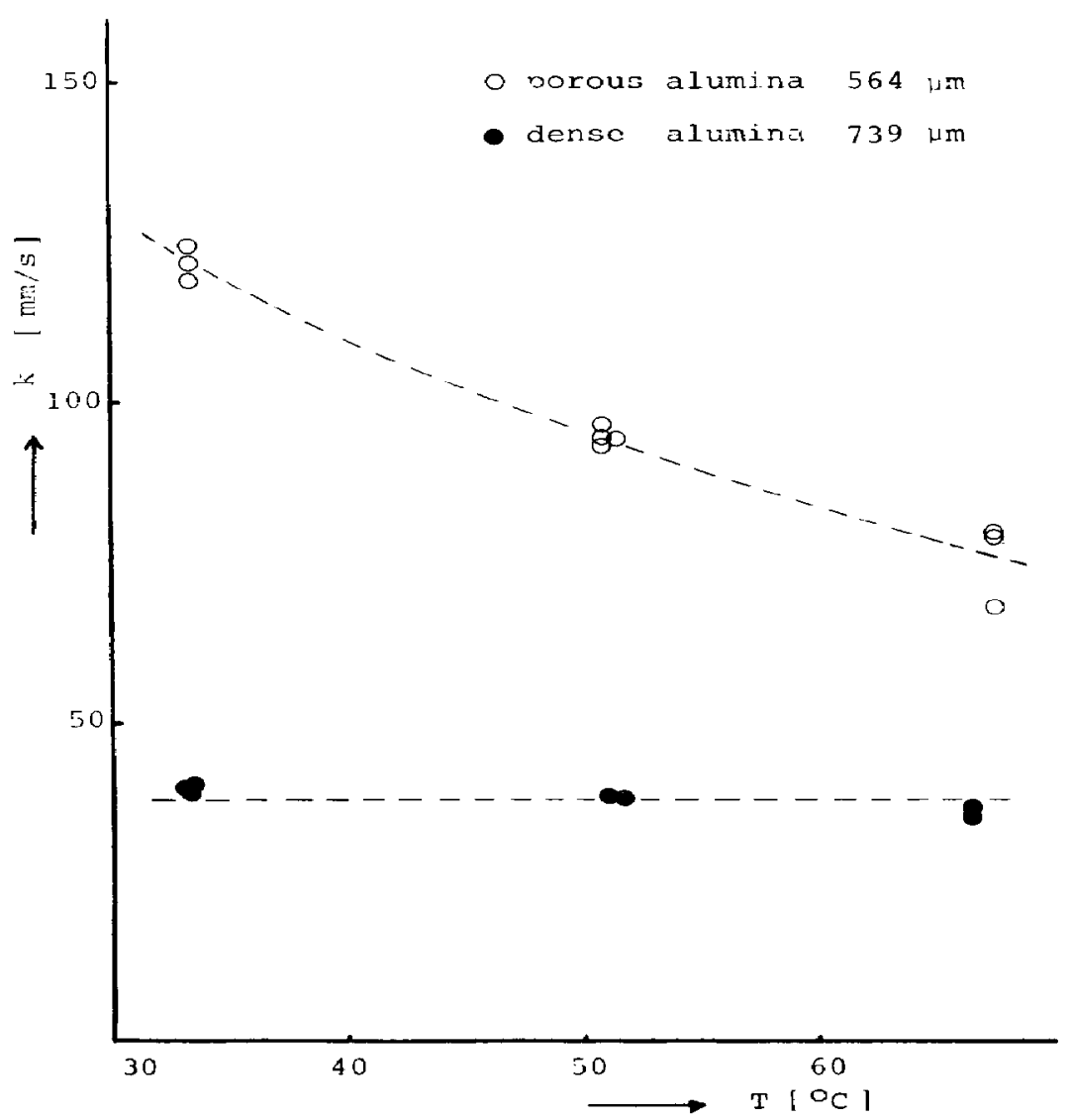

Fig. 4. Variation of observed mass transfer coefficient with temperature for a $14 \mathrm{~mm}$ naphthalene sphere in gas fluidized beds of two different bed materials; $U / U_{m f}=2$. 


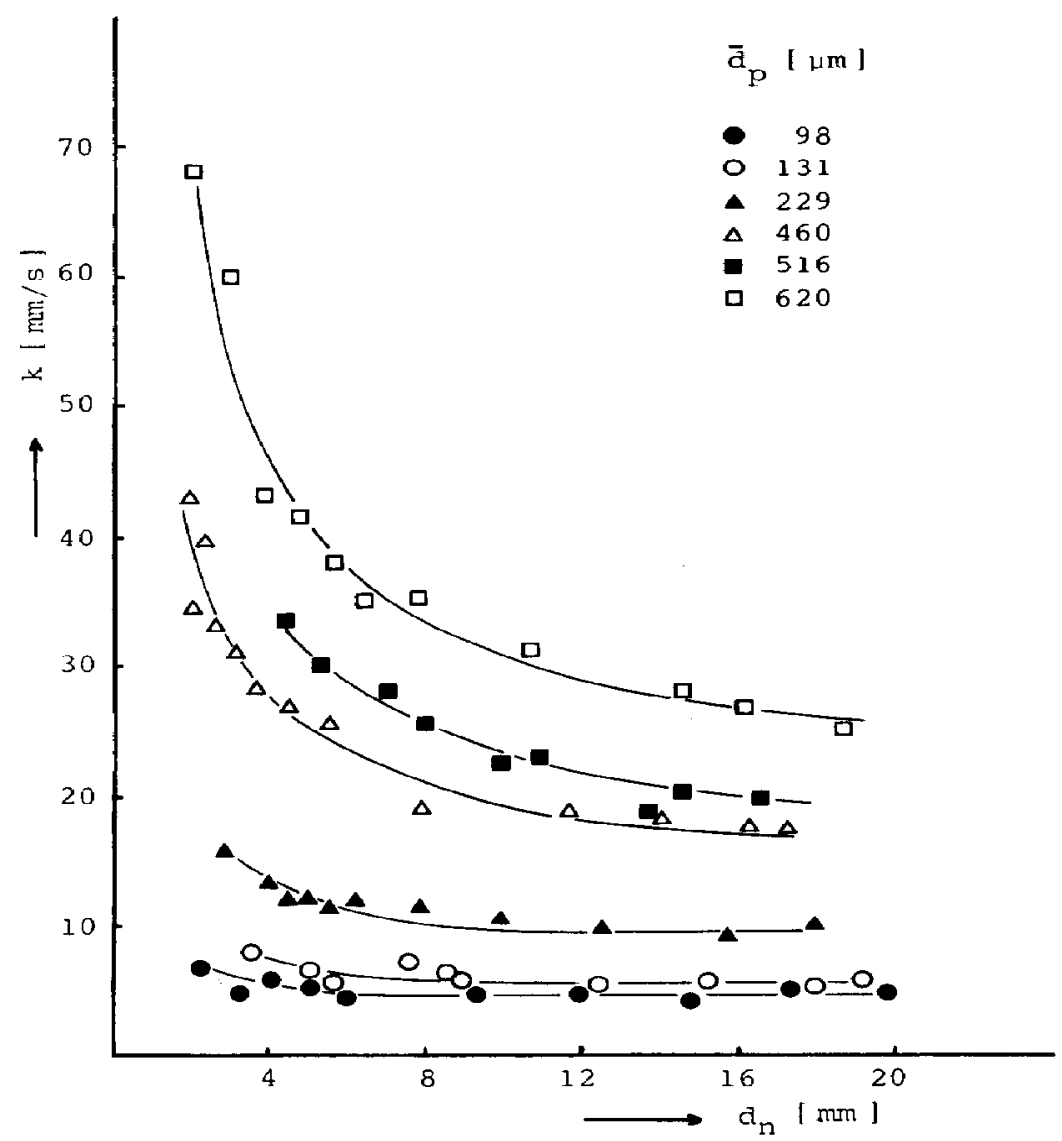

Fig. 5. Influence of the naphthalene sphere diameter on mass transfer coefficients in gas fluidized beds of glass beads; $U / U_{m f}-2$.

is the consequence of the growth of a stationary boundary layer up to a certain limit which can be characterized by a gas contact time along the naphthalene sphere of $\epsilon_{m r} d_{n} / U_{m f} \approx 0.025$ sec. Besides a gradual decrease of the porosity of the boundary layer, involving more hindering of diffusion through it, might play a significant role. The approximate boundary layer thickness can be estimated from the film theory as $\delta=D / k$.

\section{Correlation of data}

A dimensional analysis of the variables which were expected to be important in determining mass transfer rates yielded the following dimensional groups:

mass transfer factor

$$
\left(j_{D}\right)_{m f}=\frac{k}{U_{m f}}\left(\frac{v}{D}\right)^{2 / 3}
$$

Reynolds number

$$
R e_{m f}=\frac{U_{m f} d_{p}}{\left(1-\epsilon_{m}\right) v}
$$

ratio of napthalene test particle diameter and the average bed particle diameter.

$$
\frac{d_{n}}{d_{p}}
$$

The reason to relate the mass transfer factor and the Reynolds number to minimum fluidization conditions is obvious as mass transfer rates do not depend on the fluidization velocity.

First of all the results of the measurements by Hsiung and Thodos [16] for $d_{n} / d_{p}=1$, including all the runs of their main $Y$-reactor, were reanalyzed and correlated to (see Fig. 7)

$$
\epsilon_{m f}\left(j_{B}\right)_{m f}=1.61 \operatorname{Re}_{m f}^{-0.64} \text {. }
$$

Afterwards $\epsilon_{m}\left(j_{D}\right)_{m r}$ values from our own measurements were plotted against $d_{n} / d_{p}$ for the five different sized bed materials (Fig. 8). The resulting curves were extrapolated to the known values at $d_{n} / d_{p}=1$ as derived from the above mentioned correlation. This picture was now converted to the well known form of relation between mass transfer factor and the Reynolds number [24]): $\epsilon_{m f}\left(j_{D}\right)_{m f}=C \boldsymbol{R e}_{m f}^{-m}$. The value of $C$ as well as the value of $m$ appeared to depend on $d_{n} / d_{p}$. The final result of our regression analysis is presented in Fig. 9. As a best fit of all the 


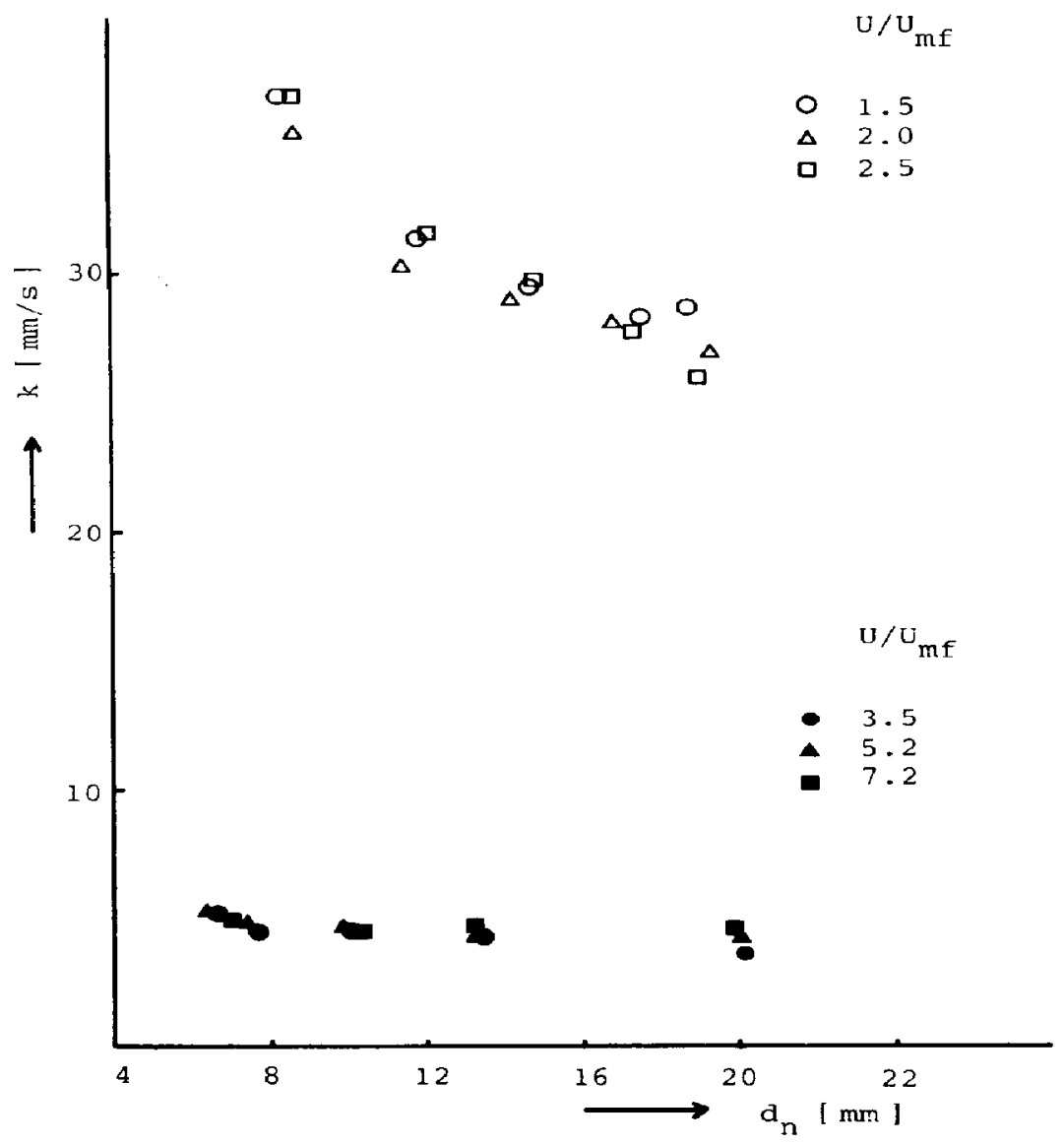

Fig. 6. Mass transfer coefficients versus naphthalene sphere diameter at various superficial velocities in gas fluidized beds of (a) $98 \mu \mathrm{m}$ glass beads (closed symbols); and (b) $620 \mu \mathrm{m}$ glass beads (open symbols).

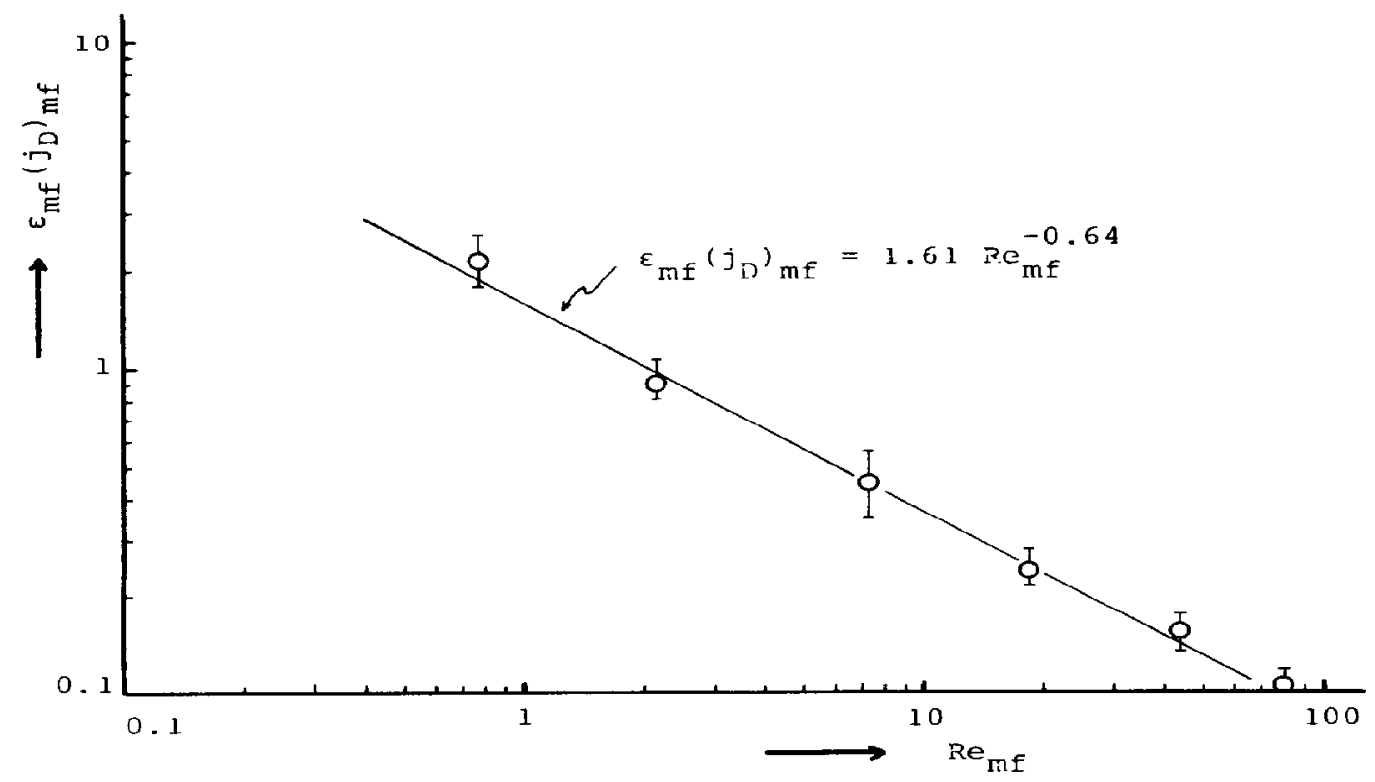

Fig. 7. Effect of the Reynolds number on the mass transfer factor at $d_{n} / d_{p}=1$; experimental data from Hsiung and Thodos\{16]. 


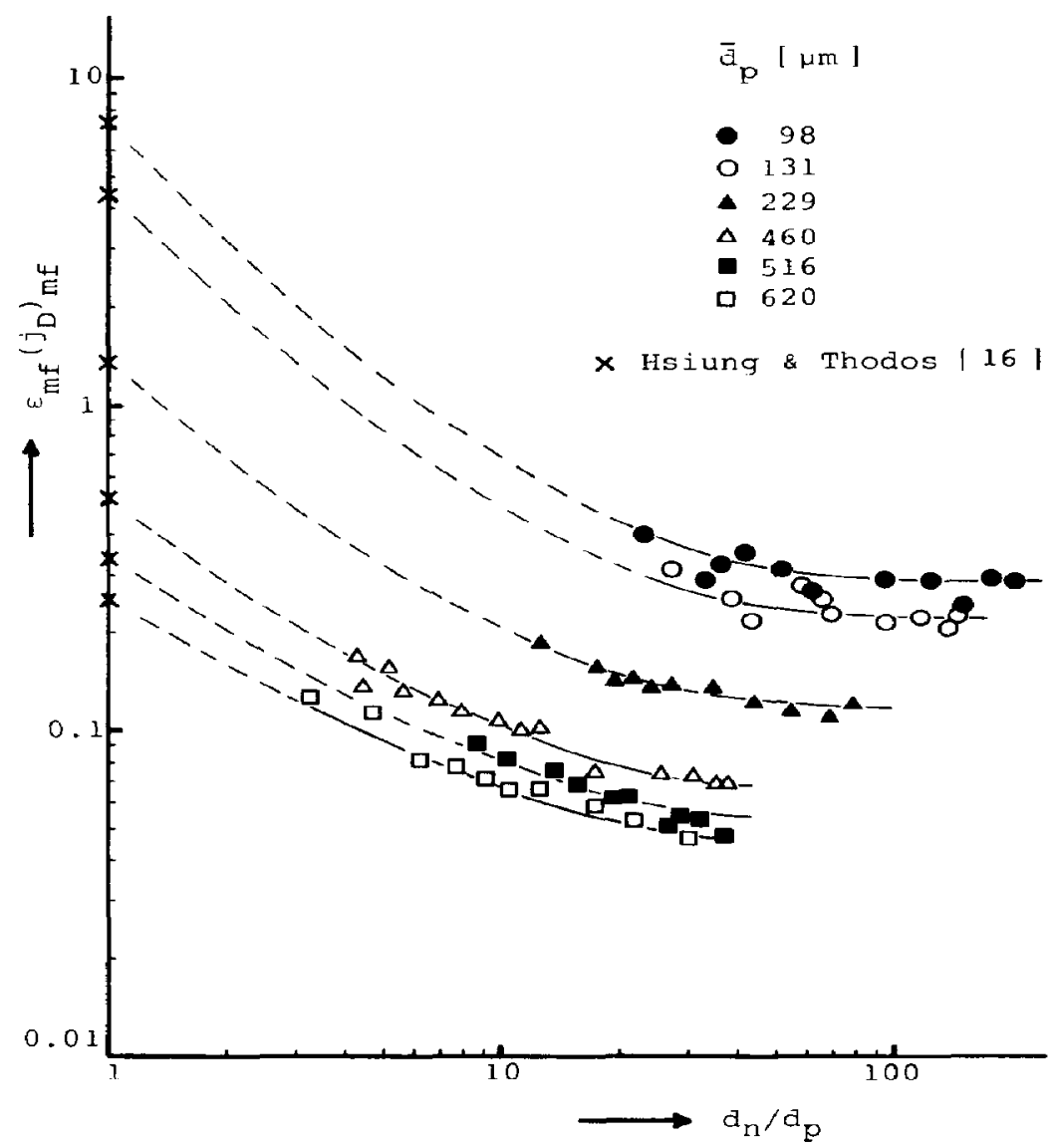

Fig. 8. Mass transfer factor versus the ratio of naphthalene sphere and bed particle diameter in gas fluidized beds of glass beads $\left(U / U_{m f}=2\right)$; extrapolation to the experimental result of $H$ siung and Thodos [16] at $d_{n} / d_{p}=1$.

results the correlation

$$
\epsilon_{m f}\left(j_{D}\right)_{m f} R e_{m f}^{m}=0.105+1.505\left(\frac{d_{n}}{d_{p}}\right)^{-1.05}
$$

with

$$
m=0.35+0.29\left(\frac{d_{n}}{d_{p}}\right)^{-0.50}
$$

is accurate within $15 \%$ and does apply if $0.1<R e_{m f}<20$ and $1 \leq d_{n} / d_{p}<200$.

\section{Packed bed measurements}

Some additional measurements of mass transfer coefficients in the same bed material as before have been carried out at velocities below $U_{m f}$. From Fig. 10 it can be seen that the results of these fixed bed measurements are quite close to our fluidized bed correlation, which confirms the conclusion of Van Heerden et $\mathrm{al}$. [17] that the rate of mass transfer in a fluidized bed is the same as in a fixed bed of similar particles, the same porosity and at the same gas velocity (it should be noted that in case of a fixed bed $j_{D}$ as well as $R e$ are related to the superficial velocity).
Other bed materials: analogy between heat and mass transfer

If bed particles have a certain capacity to adsorb naphthalene vapor on their external and internal surface area, mass transfer will increase considerably. As recognized by Van Heerden et al. [17] the transfer mechanism then becomes very similar to that of heat transfer in a fluidized bed. In their experiments mass transfer rates were measured from a naphthalene coated wall to the fluidized bed. Two kinds of bed materials were used differing in adsorption capacity over a factor 25. The difference in mass transfer coefficient however, appeared to be only a factor 2 . Similar measurements of the present investigation confirm these experiences. Figure 11 shows the results of measurements in fluidized beds of: (a) dense alumina particles (zero adsorption capacity); (b) sand particles $(0.2 \mathrm{mg} / \mathrm{g})$; and (c) porous alumina microspheres $(25 \mathrm{mg} / \mathrm{g})$.

In the first case mass transfer rates appear to be the same as predicted from the empirical correlation for glass beads (eqns 4 and 5 ). In a fluidized bed of sand particles, however, mass transfer coefficients are twice as high, and in a fluidized bed of porous alumina 


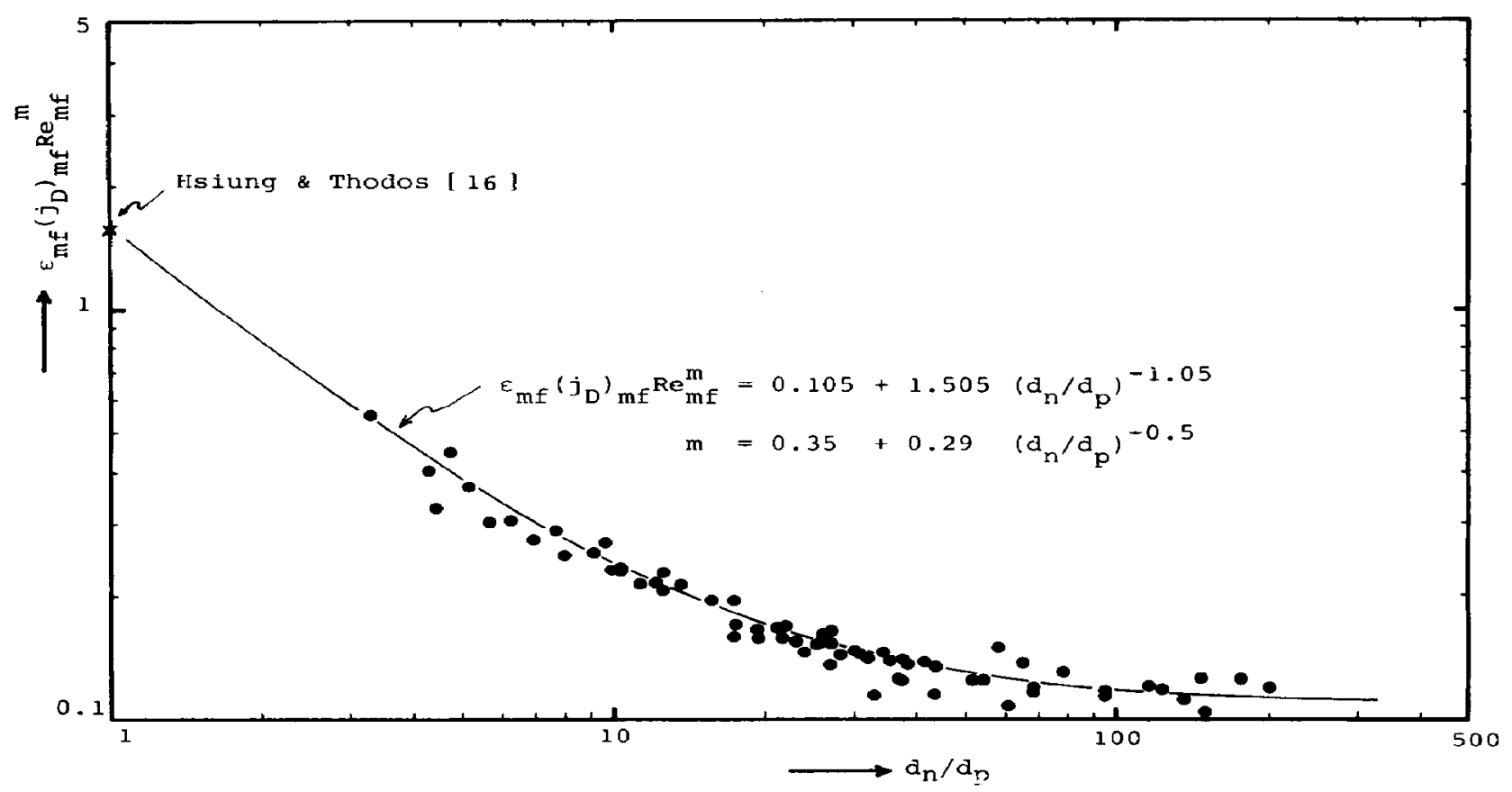

Fig. 9. Generalized result of mass transfer measurements in gas fluidized beds of glass beads, showing the effect of the ratio of naphthalene sphere and bed particle diameter; presentation of the empirical correlation; $U / U_{m r}=2$.

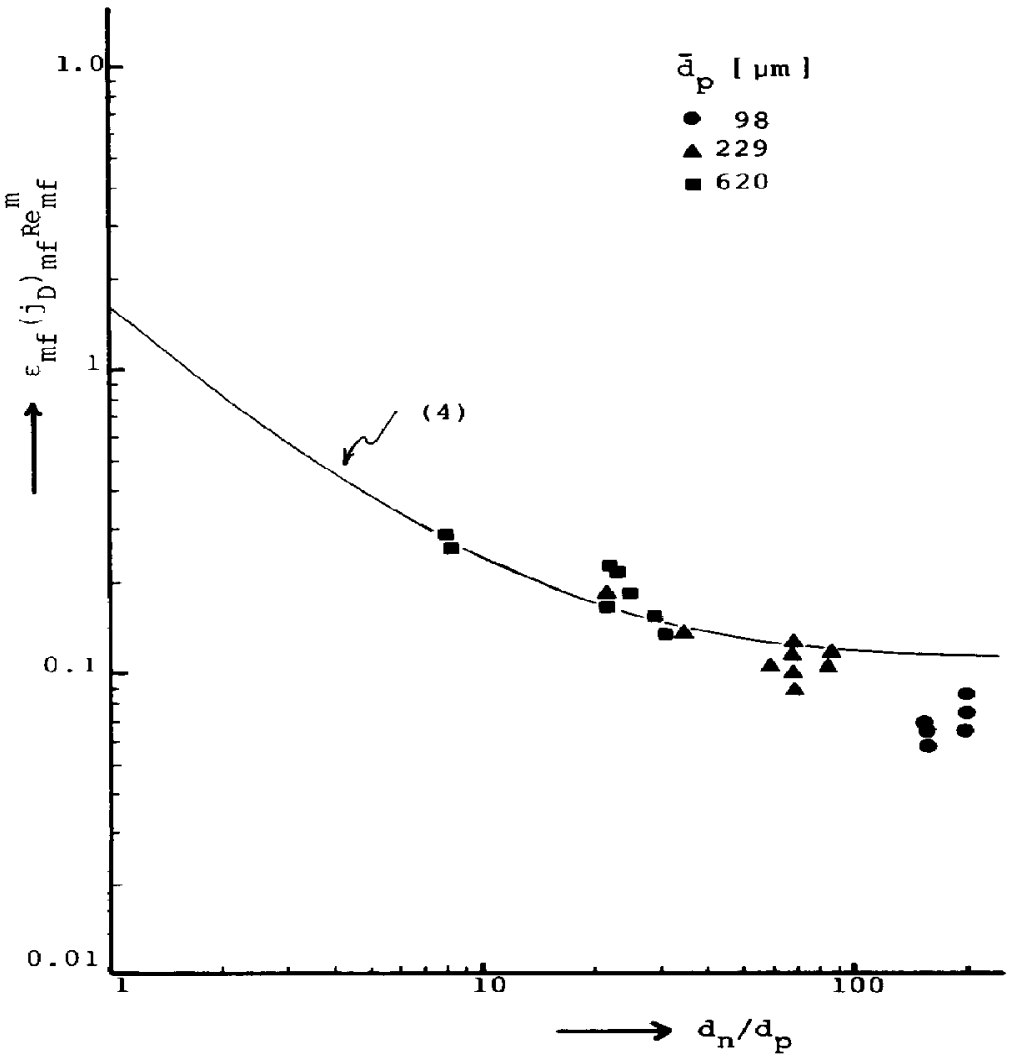

Fig. 10. Mass transfer results in fixed beds of glass beads $\left(U / U_{m f}=0.8\right)$ compared to the fluid bed empirical correlation (eqn 4). 


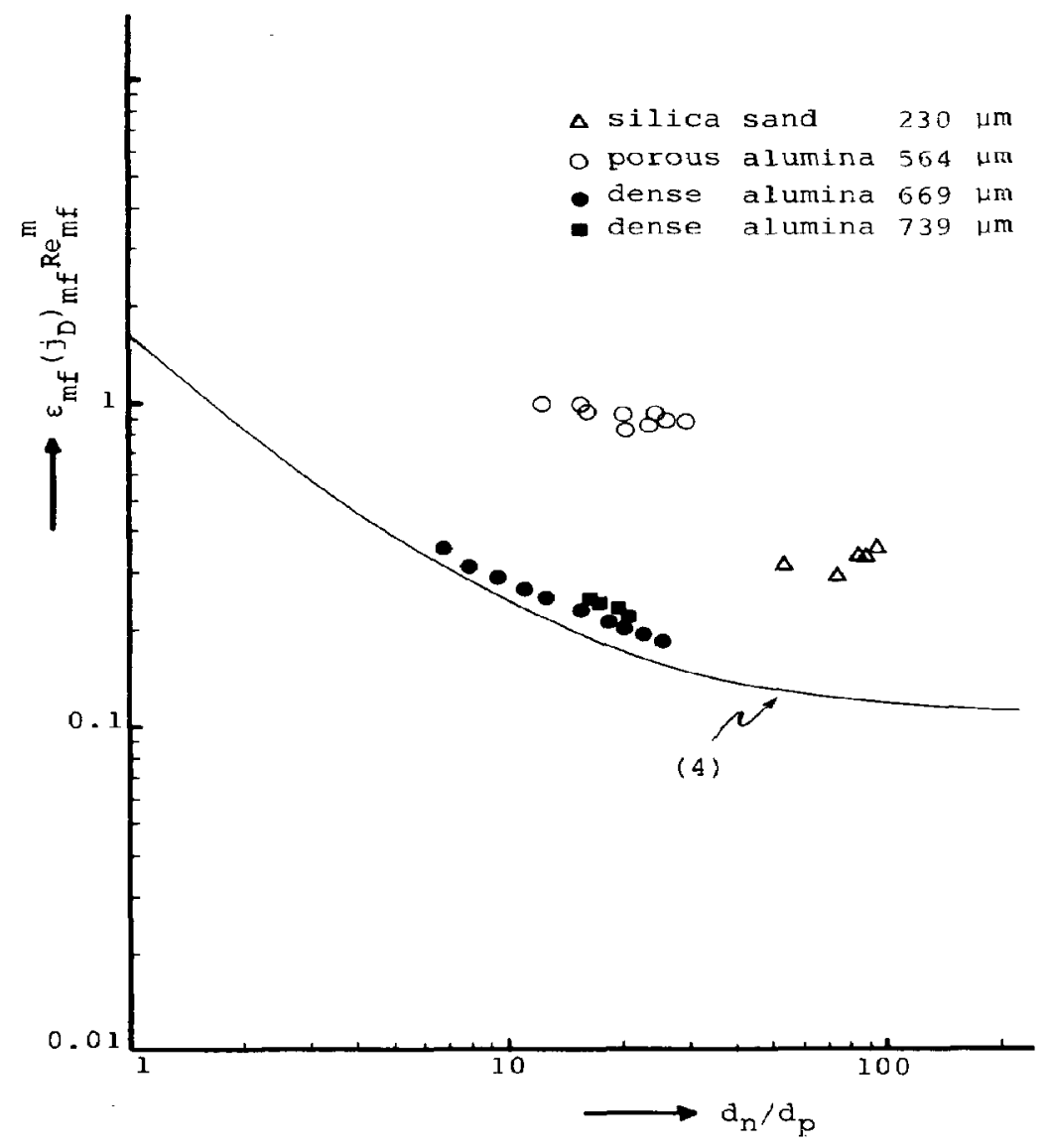

Fig. 11. Mass transfer results in gas fluidized beds of some other bed materials $\left(U / U_{m f}=2\right)$, compared to the empirical correlation for glass beads (eqn 4); open symbols-adsorbing; closed symbols-non adsorbing bed materials.

microspheres about 3 times higher than expected for similar non adsorbing bed particles.

Wall to bed heat transfer coefficients have often been related to the effective capacity of the bed by means of a square root proportionality. Mickley and Fairbanks[26] showed that such a relationship could also be deduced from the mass transfer results with naphthalene adsorbing bed materials as reported by Van Heerden et al.[17]. The contribution to convective transport by moving particles carrying with them an amount of adsorbed naphthalene is comparable to the contribution of the heat capacity of moving particles in the case of heat transfer. Following the approach of Mickley and Fairbanks, results of the present investigation concerning mass transfer in naphthalene adsorbing bed materials ((silica sand, porous alumina) lead to reasonable values of the stirring factor. For example the mass capacity of the fluidized bed consisting of porous alumina particles (564 $\mu \mathrm{m})$, which adsorb 0.025 gram naphthalene vapor per gram (see Table 2) can be calculated as $\kappa=0.025\left\{\left(1-\epsilon_{m f}\right) \rho_{p} / \epsilon_{m f} c^{*}\right\} \approx 4000$. The value of the mass transfer coefficient which has been measured is

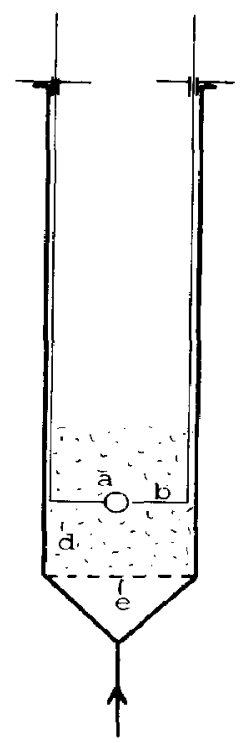

Fig. 12. Sketch of arrangement for experiments with fixed naphthalene spheres: (a) naphthalene sphere; (b) needle; (c) frame; (d) fluid bed; (e) distributor. 


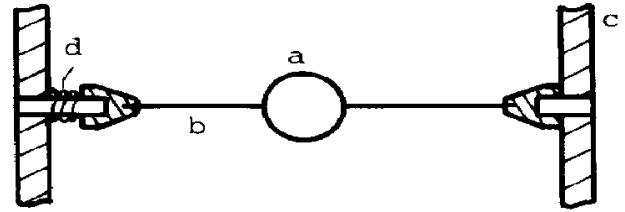

Fig. 13. Detail of Fig. 12: (a) naphthalene sphere; (b) needle; (c) frame; (d) spring.

approximately $0.08 \mathrm{~m} / \mathrm{s}$ (Fig. 4). Taking $D_{e}=D / 4$ for the effective diffusivity of naphthalene vapor in the dense phase of the fluidized bed, the stirring factor can now be deduced from the formula (see Mickley and Fairbanks [26]) $S=k^{2} / D_{e} \kappa \approx 0.8 s^{-1}$. The analogy between mass and heat transfer in fluidized beds could be clarified further by systematic research, using naphthalene adsorbing bed materials over a wide range of adsorption capacities. These bed materials should, however, be characterized sufficiently to enable a proper understanding of the transfer mechanism. In the near future we will start up such a research aimed at the analogy between mass and heat transfer in gas fluidized beds.

\section{Fixed test samples}

Naphthalene spheres were clasped between two needles which were in their turn fixed to a frame. After this frame had been inserted into the fluidized bed unit, the sphere was positioned precisely in the centre of the bed (Figs. 12 and 13). A slight modification of the construction enabled all other positions in the bed. By moving the frame up or downwards the position of the naphthalene sphere could be changed in axial direction; by the use of needles of different lengths its position was changed over the radius of the fluidized bed unit. The results of the mass transfer measurements proved, however, not to depend notably of the position of the naphthalene sphere in the bed, unless it was fixed right above the distributor. In that case mass transfer coefficients are a little higher. In Fig. 14 results of measurements with fixed test samples are compared with the correlation for freely moving test samples. There is a difference between the two series of about $20-50 \%$, mass transfer of fixed samples being the highest, probably because of an increased contact with bubbles or an increased local slip velocity. The results of Ziegler and Holmes [18] from measurements concerning mass transfer of water from a fixed sphere

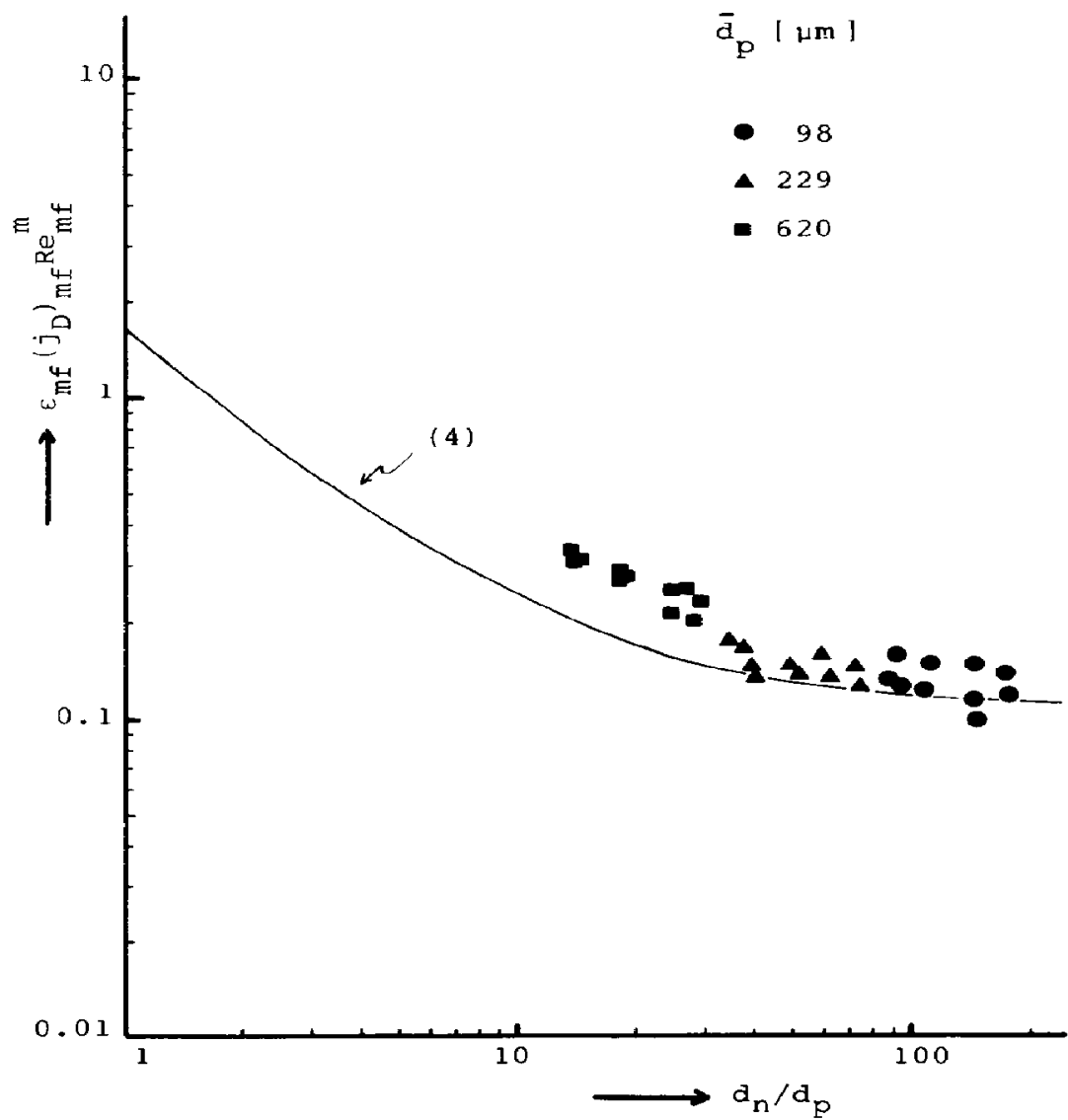

Fig. 14. Mass transfer results in gas fluidized beds of glass beads for the case of fixed naphthalene spheres compared to the empirical correlation for freely moving naphthalene spheres (eqn 4 ); $U / U_{m f}=2$. 
(0.5 in diameter) are in close agreement with those presented in figure 6 . Averaged values of $\epsilon_{m f}\left(j_{D}\right)_{m f}$ $\boldsymbol{R} e_{m f}^{m}$ were evaluated from Table 1, Ref. [18]:

fused alumina $A, \epsilon_{m f}\left(j_{D}\right)_{m f} R e_{m f}^{m}=0.12$ at $d_{n} / d_{p}=86$ $\begin{array}{lll}\text { fused alumina } B, & 0.20 & 144\end{array}$ copper spheres,

0.09

Mass transfer from a large fixed object or a wall to the fluidized bed

For large values of $d_{n} / d_{p}$ the empirical correlation for the mass transfer coefficient becomes $\epsilon_{m f}\left(j_{D}\right)_{m f} R e_{m f}^{0.36}=0.105$ as can be seen from eqn (4) and (5). Considering this expression as a result for mass transfer from a large object or a wall to the fluidized bed it would be interesting to get acquainted with results of measurements in such a system. Unfortunately there are only few experimental data available literature.

Baskakov and Suprun [19] measured mass transfer rates from fixed cylindrical naphthalene samples (of $11 \times 70 \mathrm{~mm}$ and larger sizes) to the dense phase of fluidized beds consisting of corundum or fire clay particles. However, only for corundum particles they found the influence of attrition and adsorption to be negligible. In view of our experiences with porous bed materials in relation to the effect of adsorption, their measurements in fire clay particles might be influenced by this phenomenon. Therefore we focussed on their result in beds of corundum particles. Estimating minimum fluidizing velocities of $0.4,0.2$ and $0.7 \mathrm{~m} / \mathrm{s}$ for the 500,320 and $160 \mu$, corundum particles, a value of $0.4 \mathrm{~m}$ for the bed porosity and 2.6 for the Schmidt number $\epsilon_{m f}\left(j_{D}\right)_{m f} R e_{m f}^{0.36}$ was calculated and found to be approximately 0.14 in each case. At first sight the measurements of Ziegler and Holmes [18] seem to be less useful, because the authors believed that adsorption of naphthalene on the bed particles increased the transfer rates. However, no mass capacity data were taken for the bed materials they used (dense alumina particles). In the course of our investigation it became clear that dense alumina particles do not adsorb naphthalene at all. So there is strong evidence now that mass transfer rates as measured by Ziegler and Holmes by evaporating naphthalene from coated flat plates $(5 \times 50 \mathrm{~mm}$ and larger sizes) inserted vertically into a fluidized bed of dense alumina particles, were not affected by the adsorption phenomenon. After reanalyzing their results an average value of $\epsilon_{m f}\left(j_{D}\right)_{m f} R e_{m f}^{0.36} \approx 0.15$ was calculated for the fluidized beds of 279 and $148 \mu \mathrm{m}$ alumina particles, which is

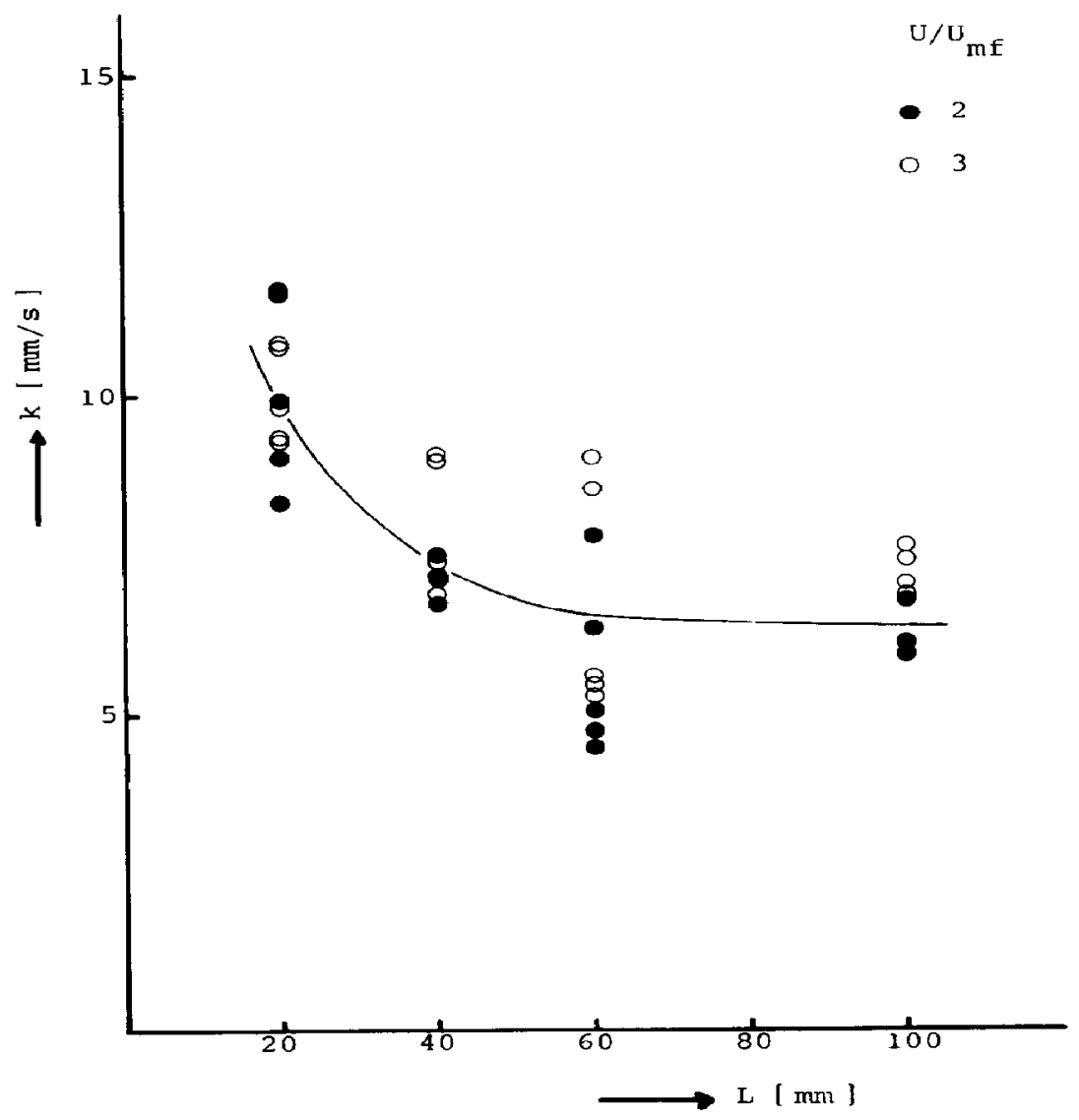

Fig. 15. Mass transfer from a naphthalene coated flat plate to a gas fluidized bed of $229 \mu \mathrm{m}$ glass beads; influence of the the plate length on the mass transfer coefficients for the two different superficial velocities. 


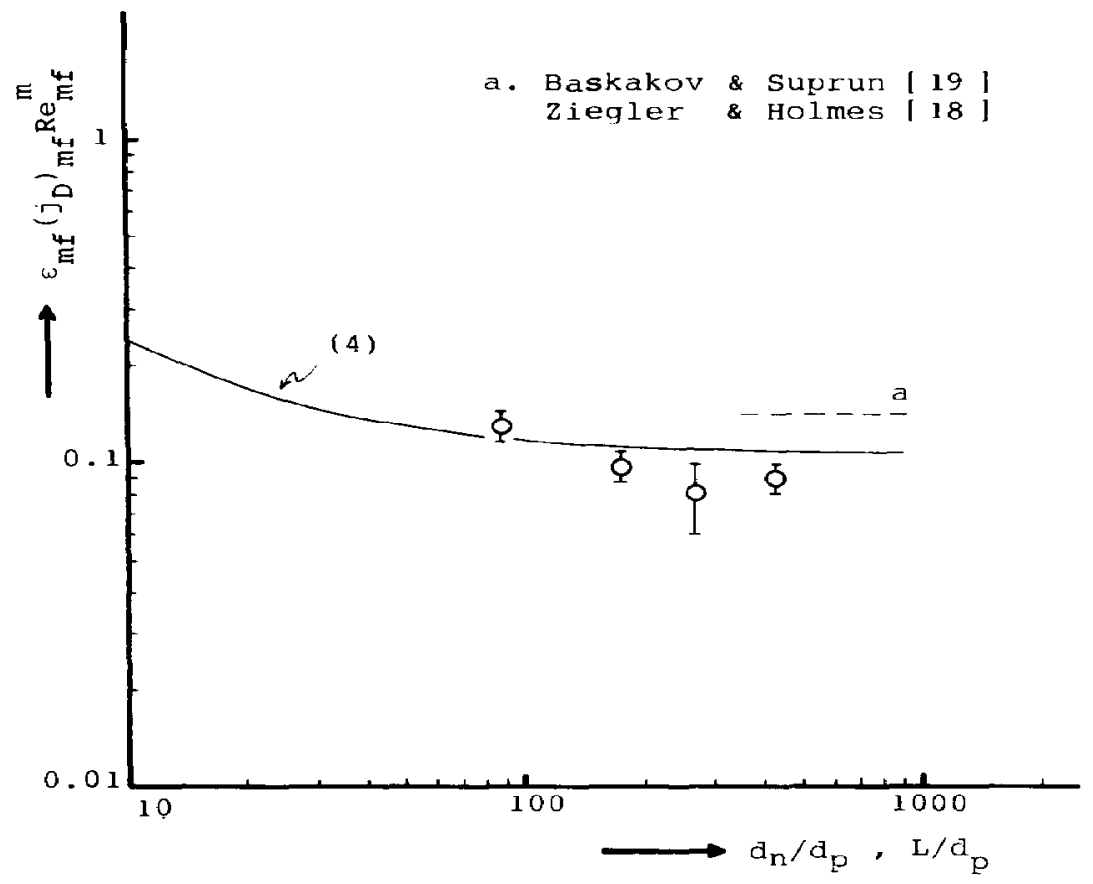

Fig. 16. Averaged results of mass transfer measurements from naphthalene coated flat plates to a gas fluidized bed of $229 \mu \mathrm{m}$ glass beads; comparison with some literature data and also with the limiting case $d_{n} / d_{p} \rightarrow \infty$ of freely moving naphthalene spheres (eqn 4 ).

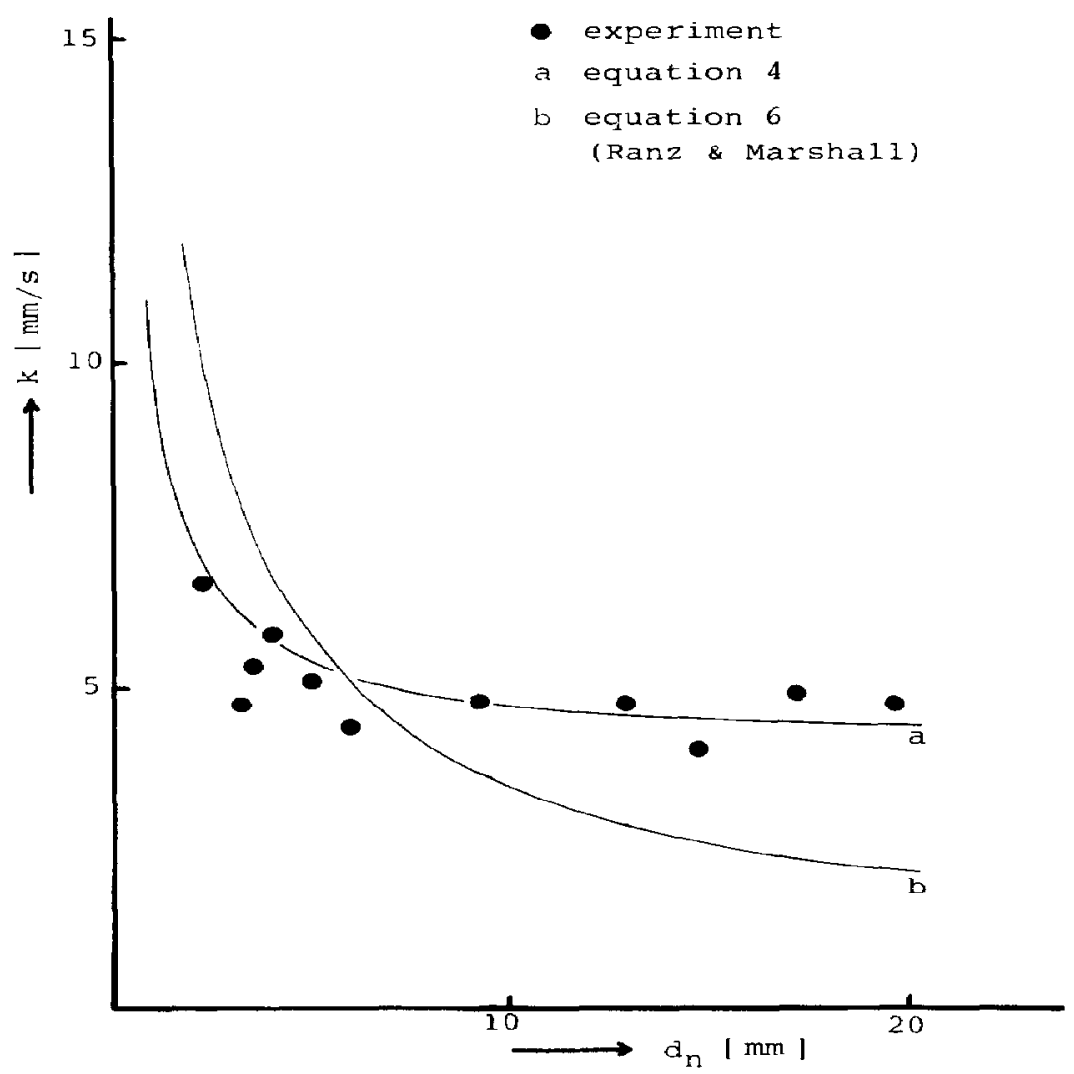

Fig. 17. Prediction of the mass transfer coefficient in a gas fluidized bed of $98 \mu \mathrm{m}$ glass beads; experimental points of the present investigation are compared with eqn (4) and with the well known Ranz and Marshall relation according to eqn (6). 
about the same as deduced from the work of Baskakov and Suprun. The effect of the test sample size was not discussed in these investigations.

To verify the preceeding data, some occasional experiments have been carried out in a fluidized bed of spherical glass beads $\left(d_{p}=229 \mu \mathrm{m}\right)$, applying the same technique as Ziegler and Holmes. A naphthalene coated (only one side) copper plate was inserted vertically into, and fixed in position at the center of the fluid bed. The width of the plate was $20 \mathrm{~mm}$ and its thickness $5 \mathrm{~mm}$. The plate length has been varied from 20 to $100 \mathrm{~mm}$. Results of these measurements are presented in Figs. 15 and 16. From the first one it is obvious that mass transfer coefficients do not notably depend on the fluidizing velocity and neither on the plate length if approximately $L>50 \mathrm{~mm}$. From the latter we may conclude now that the empirical correlation for freely moving test samples (eqns 4 and 5) links up rather well to the case of mass transfer from a large object or a wall to the fluid bed, if $d_{n} / d_{p}>100$.

\section{PREDICTION OF MASS TRANSFER COEFFICIENTS}

Calculating the Sherwood number as $k d_{n} / D$ and the Reynolds number as $U_{m} d_{n} /\left(1-\epsilon_{m}\right) v$, the application of the Ranz-Marshall equation

$$
S h=2+0.6 R e^{0.50} S c^{0.33}
$$

for the prediction of mass transfer coefficients in fluidized beds leads to serious errors and must be dissuaded. Figures 17 and 18 illustrate the discrepancy between such predictions and those from eqn (4).

In attempt to correlate their experimental results of diffusion limited coke particle combustion in a fluidized bed, some authors tried a modified form of the Ranz-Marshall equation. For example Chakraborty and Howard[10] and also La Nauze and Jung[21] defined a Reynolds number using the superficial velocity instead of the minimum fluidization velocity. The latter proposed the following expression

$$
S h=2 \epsilon+0.69\left(\frac{U d_{c}}{\epsilon v}\right)^{0.50} S c^{0.33}
$$

which happened to fit their experimental results rather well. This correlation, however, predicts a significant effect of the superficial velocity, con-

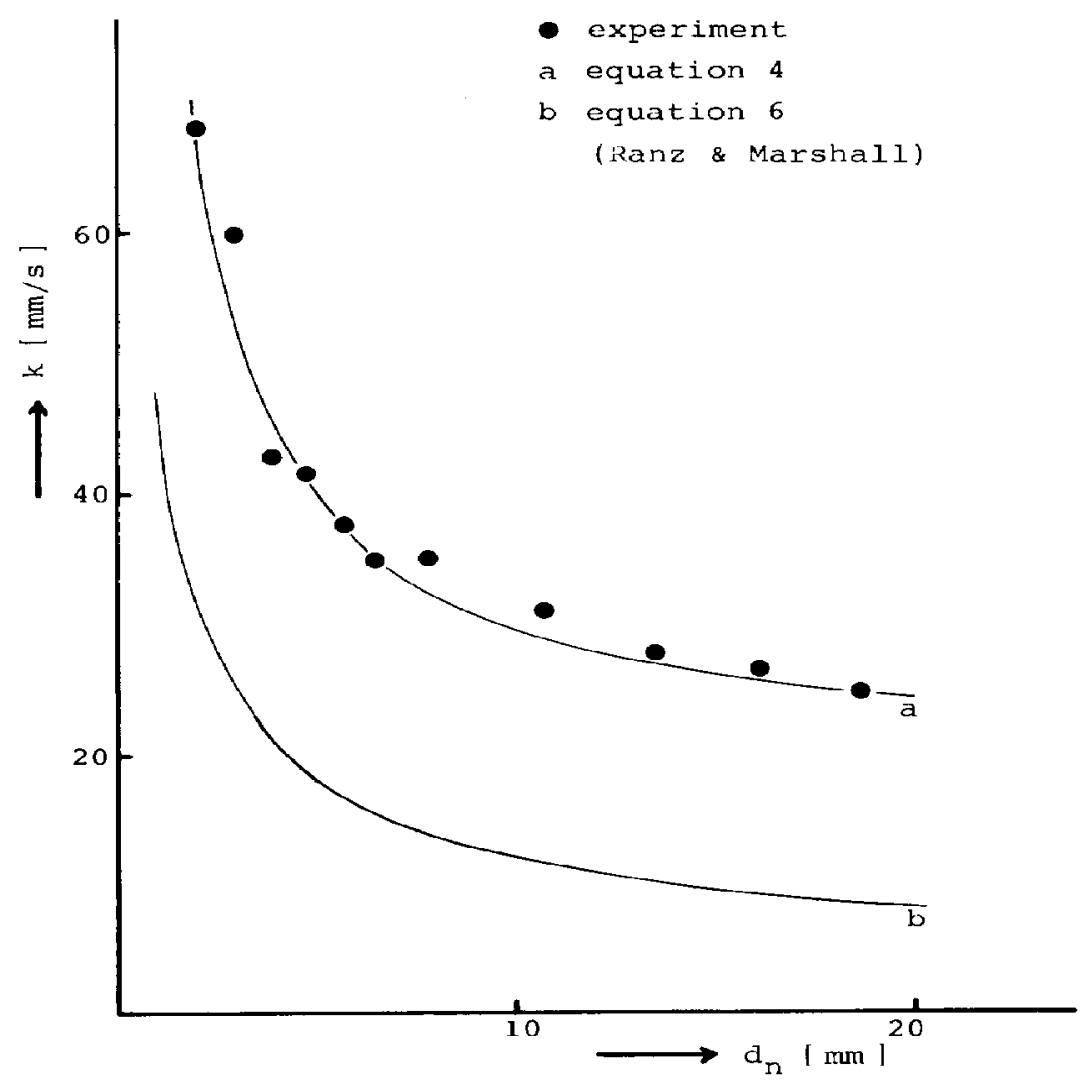

Fig. 18. Prediction of mass transfer coefficient in a gas fluidized bed of $620 \mu \mathrm{m}$ glass beads; experimental points of the present investigation are compared with eqn (4) and with the well known Ranz and Marshall relation according to eqn (6). 
tradicting an important conclusion of the present investigation. Moreover, this parameter has not been varied at all in their experiments. The results of La Nauze and Jung for the combustion of coke particles in a fluidized bed of $780 \mu \mathrm{m}$ sand particles have been reanalyzed in terms of mass transfer factors for a comparison with eqn (4). After an additional estimate of parameters at combustion temperature and assuming that the heterogeneous reaction at the carbon particle surface was $\mathrm{C}+\mathrm{O}_{2} \rightarrow \mathrm{CO}_{2}$, the value of the mass transfer coefficient $k$ could be evaluated from Fig. 8 and eqn (8), both from reference[21]. Figure 19 shows a rather good consistency, especially for the smaller coke particles.

By substituting the Ergun equation for the minimum fluidization velocity [27] into eqn (4), this empirical correlation can be rewritten to

$$
\begin{aligned}
\frac{S h}{S c^{1 / 3}} \approx & \frac{1-\epsilon_{m f}}{\epsilon_{m f}}\left(\frac{\epsilon_{m f}^{3}}{150\left(1-\epsilon_{m f}\right)^{2}} \cdot A r\right)^{1-m} \\
& \times\left(1.5+0.1 \frac{d_{n}}{d_{p}}\right)
\end{aligned}
$$

with

$$
S h=\frac{k d_{n}}{D}
$$

and

$$
A r=\frac{g d_{p}^{3}}{v^{2}} \frac{\rho_{p}}{\rho}
$$

In Table 3 the relationship between the Sherwood and Archimedes number, expressed as

$$
S h / S c^{1 / 3}=\alpha A r^{\beta}
$$

is compared to the theoretical result obtained by Tamarin [20]. Values of $\alpha$ and $\beta$ are reported, belonging to a bed voidage at minimum fluidization of $\epsilon_{m f}=0.4$ and calculated for a number of different ratios $d_{n} / d_{p}$.

The theoretical approach of Tamarin, starting with the well known solution of the Prandtl boundary layer equation for a sphere in a uniform flow, seems to fail. From our measurements it became clear that the way in which the physical properties of the bed

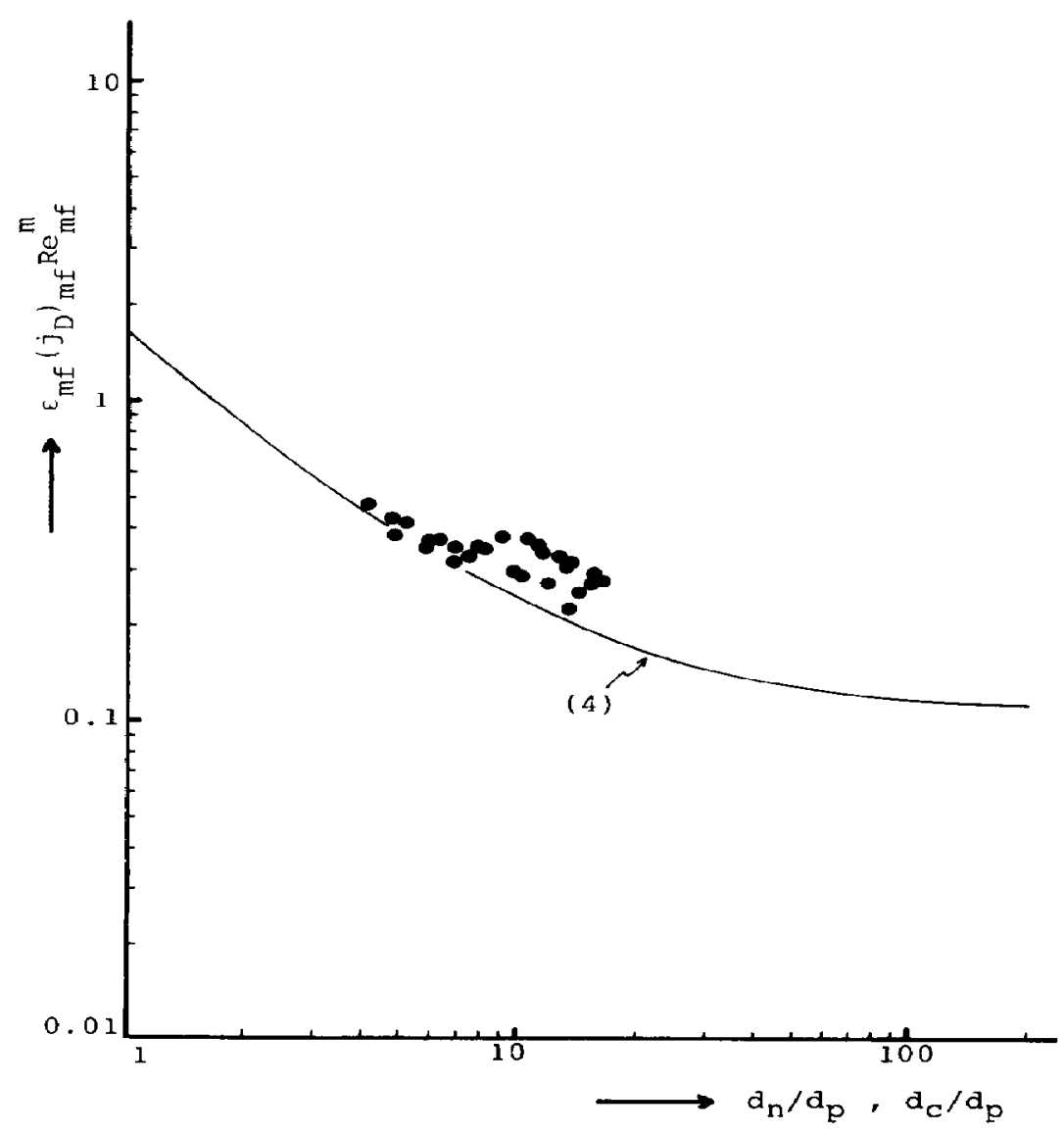

Fig. 19. Mass transfer data calculated from fluidized bed coke particle combustion by La Nauze and Jung[21] $\left(U / U_{m f}=2.6\right)$ compared with the result of the present investigation (eqn 4$)$. 
Table 3. Relationship between the Sherwood number and the Archimedes number at $\epsilon_{m f}=0.4 ; S h / S c^{1 / 3}=\alpha A r^{\beta}$

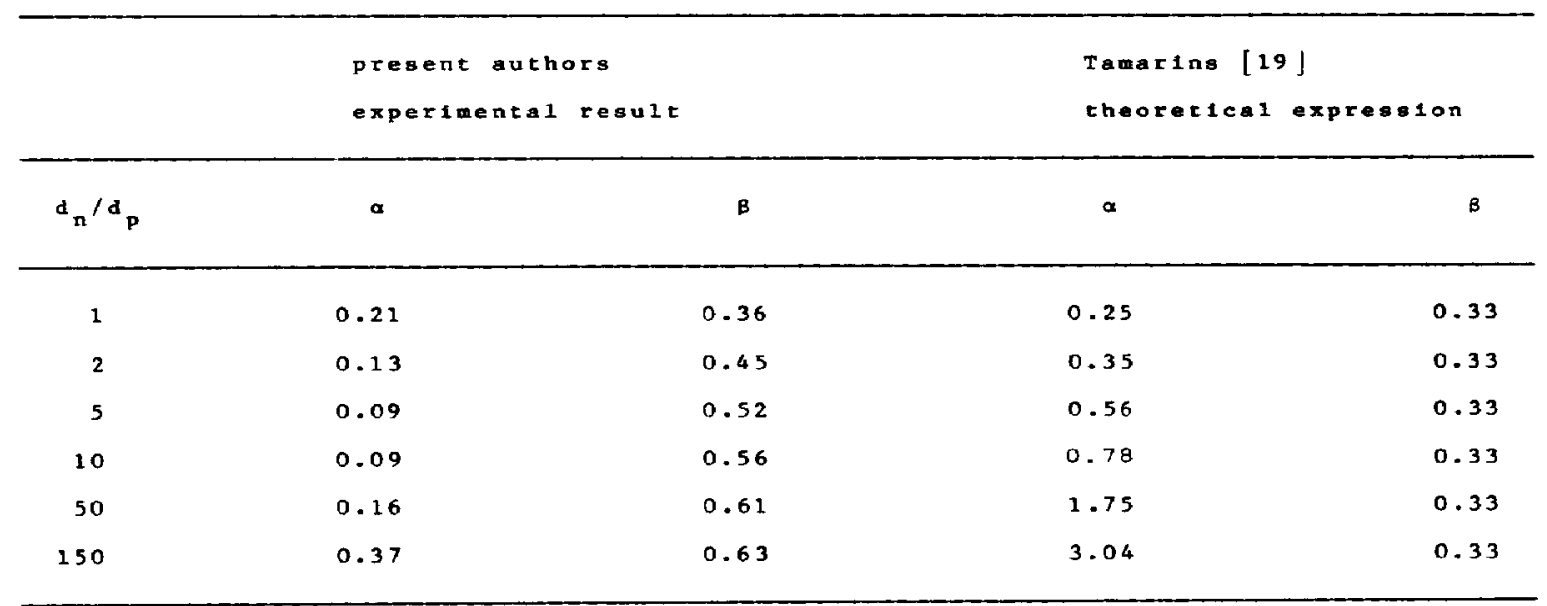

material affect the transfer processes is not constant but depends on $d_{n} / d_{p}$ (Sh $\sim A r^{1-m}, m$ varies from 0.64 to 0.35). Besides, for a certain bed material the Sherwood number is not proportional to $\left(d_{n} / d_{p}\right)^{0.50}$ as found by Tamarin, but approximately to $(1.5+0.1$ $d_{n} / d_{p}$ ) (see Table 3 ). So we may say that there is still a need for a proper boundary layer model describing the mass transfer laws in a system of single active particles dispersed in a (fixed or) fluidized bed of inert material.

\section{CONCLUSIONS}

Mass transfer coefficients have been measured from a freely moving single sphere to the dense phase of a gas fluidized bed over a wide range of bed particle and test sample diameters. Not every kind of bed material is suited for such measurements. The effect of mechanical erosion of the test sample and/or adsorption of naphthalene vapor of the bed material was investigated and it was demonstrated that only non porous spherical bed particles should be used. From experimental results the following conclusions may be drawn:

- Mass transfer coefficients decrease with increasing test sample diameter up to a certain limit which may be roughtly characterized by a gas contact time of 25 $\operatorname{msec}\left(\epsilon_{m j} d_{n} / U_{m j}\right)$.

-Mass transfer coefficients do not depend on the superficial velocity.

- Bed particle diameter and thus minimum fluidization velocity has a major influence on mass transfer results.

- To predict mass transfer coefficients the following equations are recommended:

$$
\begin{gathered}
\epsilon_{m f}\left(j_{D}\right)_{m f} R_{m f}^{m}=0.105+1.505\left(\frac{d_{n}}{d_{p}}\right)^{-1.05} \\
m=0.35+0.29\left(\frac{d_{n}}{d_{p}}\right)^{-0.50}
\end{gathered}
$$

valid for $0.1<R e_{m f}<20$ and $1 \leq d_{n} / d_{p}<200$.
These relations show good consistency with known experimental data for the extreme cases of $d_{n} / d_{p}=1$ and $d_{n} / d_{p} \rightarrow \infty$.

- Mass transfer coefficients in fixed beds can be calculated from the same formula if only the minimum fluidization velocity in the Reynolds number is replaced by the superficial velocity of the fixed bed.

- Results of measurements with fixed samples are somewhat higher $(20-50 \%)$ than in the case of freely moving samples.

Mass transfer coefficients in fluidized beds of naphthalene adsorbing particles appeared to be much higher than expected for beds of similar non adsorbing particles. The increase of the transfer coefficients as a consequence of the mass capacity of the bed seems to be consistent with Mickley and Fairbanks[26] theory based on the analogy between mass and heat transfer in fluidized beds.

-Although the empirical correlation, represented by eqns (4) and (5), is entirely based on measurements at temperatures of about $65^{\circ} \mathrm{C}$, the agreement with combustion experiments at much higher temperatures was quite satisfactory.

\section{NOTATION}

$A r=\rho_{p} g d_{p}^{3} / \rho v^{2}$, Archimedes number, dimensionless

$c_{0}$ naphthalene vapor concentration in the dense phase of the fluidized bed, $\mathrm{kg} / \mathrm{m}^{3}$

$c^{*}$ naphthalene vapor concentration at the surface of the naphthalene sphere, $\mathrm{kg} / \mathrm{m}^{3}$

$\Delta c=c^{*}-c_{o}$, driving force for mass transfer, $\mathrm{kg} / \mathrm{m}^{3}$

$C$ constant in Ref. [24]

$d_{c}$ coke particle diameter, $\mathrm{m}$

$d_{n}$ naphthalene sphere diameter, $\mathrm{m}$

$d_{p}$ bed particle diameter, $m$

$d_{p}$ average bed particle diameter, $\mathrm{m}$

$D$ diffusion coefficient (naphthalene vapor in air), $\mathrm{m}^{2} / \mathrm{s}$

$g$ acceleration of gravity, $\mathrm{m} / \mathrm{s}^{2}$

$\Delta \mathscr{G}$ weight loss of the naphthalene sphere, $\mathrm{kg}$ 
$j_{D}=k S c^{2 / 3} / U$, mass transfer factor as used in Ref.[16], dimensionless

$\left(j_{D}\right)_{m f}=k S c^{2 / 3} / U_{m f}$, mass transfer factor, dimensionless

$k$ mass transfer coefficient, $\mathrm{m} / \mathrm{s}$

$L$ length of a naphthalene coated flat plate, $m$

$m$ exponent of the Reynolds number given by eqn (5), dimensionless

$p^{*}$ partial saturated vapor pressure of naphthalene, $\mathrm{mm} \mathbf{H g}$

$\operatorname{Re}=U d_{p} / v$, Reynolds number as used in Ref.[16], dimensionless

$R e_{m f}=U_{m f} d_{p} /\left(1-\epsilon_{m}\right) v$, Reynolds number, dimensionless

$S$ stirring factor, $\mathrm{s}^{-1}$

Sc $=v / D$, Schmidt number, dimensionless

Sh $=k d_{n} / D$, Sherwood number, dimensionless

$\Delta t$ time increment, $\mathrm{s}$

$T$ temperature, $\mathrm{K}$

$U$ superficial velocity, $\mathrm{m} / \mathrm{s}$

$U_{m f}$ superficial velocity at minimum fluidization conditions, $\mathrm{m} / \mathrm{s}$

Greek symbols

$\alpha$ coefficient in eqn (8), dimsionless

$\beta$ exponent in eqn (8), dimensionless

$\delta$ thickness of concentration boundary layer around the naphthalene sphere, $\mathrm{m}$

$\epsilon_{m f}$ bed voidage at minimum fluidization conditions, dimensionless

$\kappa$ mass capacity of bed material, dimensionless

$v$ kinematic viscosity of air, $\mathrm{m}^{2} / \mathrm{s}$

$\rho$ density of air, $\mathrm{kg} / \mathrm{m}^{3}$

$\rho_{p}$ particle density of bed material, $\mathrm{kg} / \mathrm{m}^{3}$

REFERENCES

[1] Park D., Levenspiel C. and Fitzgerald T. J., Chem. Engng Sci. 198035296.

[2] Avedesian M. M. and Davidson J. F., Trans. Inst. Chem. Engrs 197351121.
[3] Gibbs B. M., Institute of Fuel, Symp. Ser. No. 1, Paper A5, London 1975.

[4] Horio M. and Wen C. Y., A.I.Ch.E. Symp. Ser. No. 176197874101 .

[5] Ranz W. E. and Marshall W. R., Jr., Chem. Engng Prog. 195248 141, 173.

[6] Baron R. E., Beer J. M., Borghi G., Hodges J. L. and Sarofim A. F., Proc. 5th Int. Conf. on Fluidized Combustion. Washington, D.C., Dec. 1977.

[7] Leung L. S. and Smith I. W., Fuel 197958354.

[8] Donsi G., Massimilla L., Miccio M., Russo G. and Stecconi P., Comb. Sci. Tech. 19792125.

[9] Saxena S. C. and Rehmat A., Proc. 6th Int. Conf. on Fluidized Combustion, Atlanta, Georgia, April 1980.

[10] Chakraborty R. K. and Howard J. R., J. Inst. Energy March 198155.

[11] Schlünder E. U., Chem. Engng Sci. 197732845.

[12] Thoenes D., Jr. and Kramers H., Chem. Engng Sci. 19588271 .

[13] Bar-Ilan M. and Resnick W., Ind. Engng Chem. 1957 49313.

[14] Resnick W. and White R. R., Chem. Engng Prog. 1949 45377.

[15] Chu J. C., Kalil J. and Wetteroth W. A., Chem. Engng Prog. 195349141.

[16] Hsiung T. H. and Thodos G., Chem. Engng Sci. 1977 32581 .

[17] van Heerden C., Nobel A. P. P. and van Krevelen D. W., Ind. Engng Chem. 1953451237.

[18] Ziegler E. N. and Holmes J. T., Chem. Engng Sci. 1966 21117

[19] Baskakov A. P. and Suprun V. M., Sov. Chem. Ind. 1970961.

[20] Tamarin A. I., J. Engng Phys. 1981411346.

[21] La Nauze R. D. and Jung K., Proc. 7th Int. Conf. on Fluidized Combustion, Philadelphia October 1982.

[22] Beilsteins Handbuch der Organische Chemie. Springer Verlag, Berlin 1922.

[23] Chemical Engineers Handbook (Edited by Perry R. H. and Chilton C. H.). McGraw-Hill, New York 1973.

[24] International Critical Tables, Vol. 3, p. 208. McGrawHill, New York 1928.

[25] Beek W. J., Mass transfer in fluidized beds. Fluidization (Edited by Davidson J. K. and Harrison D.)., Academic Press, New York 1971.

[26] Mickley H. S. and Fairbanks D. F., A.I.Ch.E.J. 1955 1374.

[27] Ergun S., Chem. Engng Prog. 19524889. 